Review

\title{
Advanced Cell Culture Techniques for Cancer Drug Discovery
}

\author{
Carrie J. Lovitt, Todd B. Shelper and Vicky M. Avery *
}

Discovery Biology, Griffith University, N27, Don Young Road, Nathan, Queensland, 4111, Australia; E-Mails: carrie.lovitt@griffithuni.edu.au (C.J.L.); t.shelper@griffith.edu.au (T.B.S.)

* Author to whom correspondence should be addressed; E-Mail: v.avery@griffith.edu.au; Tel.: +61-07-3735-6056; Fax: +61-07-3735-6001.

Received: 24 February 2014; in revised form: 16 May 2014 / Accepted: 22 May 2014 /

Published: 30 May 2014

\begin{abstract}
Human cancer cell lines are an integral part of drug discovery practices. However, modeling the complexity of cancer utilizing these cell lines on standard plastic substrata, does not accurately represent the tumor microenvironment. Research into developing advanced tumor cell culture models in a three-dimensional (3D) architecture that more prescisely characterizes the disease state have been undertaken by a number of laboratories around the world. These 3D cell culture models are particularly beneficial for investigating mechanistic processes and drug resistance in tumor cells. In addition, a range of molecular mechanisms deconstructed by studying cancer cells in 3D models suggest that tumor cells cultured in two-dimensional monolayer conditions do not respond to cancer therapeutics/compounds in a similar manner. Recent studies have demonstrated the potential of utilizing 3D cell culture models in drug discovery programs; however, it is evident that further research is required for the development of more complex models that incorporate the majority of the cellular and physical properties of a tumor.
\end{abstract}

Keywords: 3D culture; microenvironment; drug resistance; tumor models; high-throughput screening

\section{Introduction}

Historically, the only procedures developed for whole cell-based screening assays were those utilizing a flat layer of cells attaching to various plastic substrata. However, it is now generally accepted that culturing cells in these two-dimensional (2D) conditions is not physiologically relevant, 
and difficulties may be encountered downstream with translation in vivo. The tissue-specific architecture, along with elements in the surrounding microenvironment, are essential components of a tumor and can be at least partially recapitulated utilizing three-dimensional (3D) cell culture models [1,2].

High-throughput screening (HTS) using cell-based assays has frequently been the starting point for identifying novel compounds in drug discovery programmes. The procedures in place for the development of drugs involve thorough evaluation of novel drug candidates in both pre-clinical and clinical phases. Through these drug development practices, the attrition rates of drug candidates for cancer are significant, being approximately 95\% [3]. The development of more biologically relevant in vitro tumor models may ultimately result in improved translation and a reduction in number of the animal models required in drug discovery programmes [4].

This review focuses on the culturing of cell lines representative of solid cancers in advanced cell culture conditions. We discuss the molecular aspects of cells cultured in $3 \mathrm{D}$ and their relevance to cancer, focusing on key examples from the literature. We will also examine the 3D models that have been successfully implemented in early stage compound screening and the future of in vitro cell-based assays in cancer drug discovery practices.

\section{Modeling Cancer in 3D Cell Culture}

A range of $3 \mathrm{D}$ cell culture techniques have been developed, which can be applied to various research applications including cancer drug discovery. However, there are differing interpretations of what culturing in the third dimension actually means. For the purposes of this review, the term shall be used in reference to cells assembled into 3D structures which are cultured using either anchorage-independent methodology (without the use of a substrate for cellular attachment) or anchorage-dependent conditions (utilizing a substrate which promotes cellular attachment). The phenotypic characteristics of cancer cells cultured in a 3D model are evident in comparison to cells grown as planar cultures (Figure 1).

Anchorage-independent 3D cell culture methods involve the aggregation of cells in non-adherent culture conditions where there is no substrate, such as extracellular matrix (ECM) proteins available for cellular attachment. This 3D cell culture method can be achieved by using low-attachment plates [5] and through coating surfaces, for example with poly-hydroxyethyl methacrylate (poly-HEMA) [6] or agarose [7]. Another approach is the hanging drop method, where a drop of media containing a cell suspension promotes cell-to-cell interactions within the confines of the drop [8]. 3D cultures can also be generated in an anchorage-independent manner by culturing cells with soft agar [9]. An additional anchorage-independent 3D environment can be established with the use of pre-fabricated scaffolds, which consist of porous materials to support the growth of 3D structures [10]. Furthermore, spheroids can be created as a result of agitation procedures such as spinner flasks or a gyratory shaker [11]. The above-mentioned approaches generate types of spheroids which are commonly referred to as multicellular tumor spheroids (MCTS) in cancer research. These spheroids may exhibit tumor-specific characteristics such as heterogeneous proliferation rates, nutrient and oxygen gradients, a central region of necrosis as well as cell-to-cell and ECM-to-cell contacts in a 3D context [12-14]. 
Figure 1. Phenotypic properties of a panel of breast cancer cell lines cultured in two-dimensional (2D) and three-dimensional (3D) cell culture systems. Brightfield (BF) and immunofluorescence (IF; central Z-slice through a spheroid) microscopy illustrate 2D cell cultures and 3D structures unique to each cell line. MDA-MB-231 in 2D (A) and 3D (A', A'), MCF-7 in 2D (B) and 3D (B', B'') and BT-474 in 2D (C) and 3D (C', C',). Scale bar $=50 \mu \mathrm{m}$.

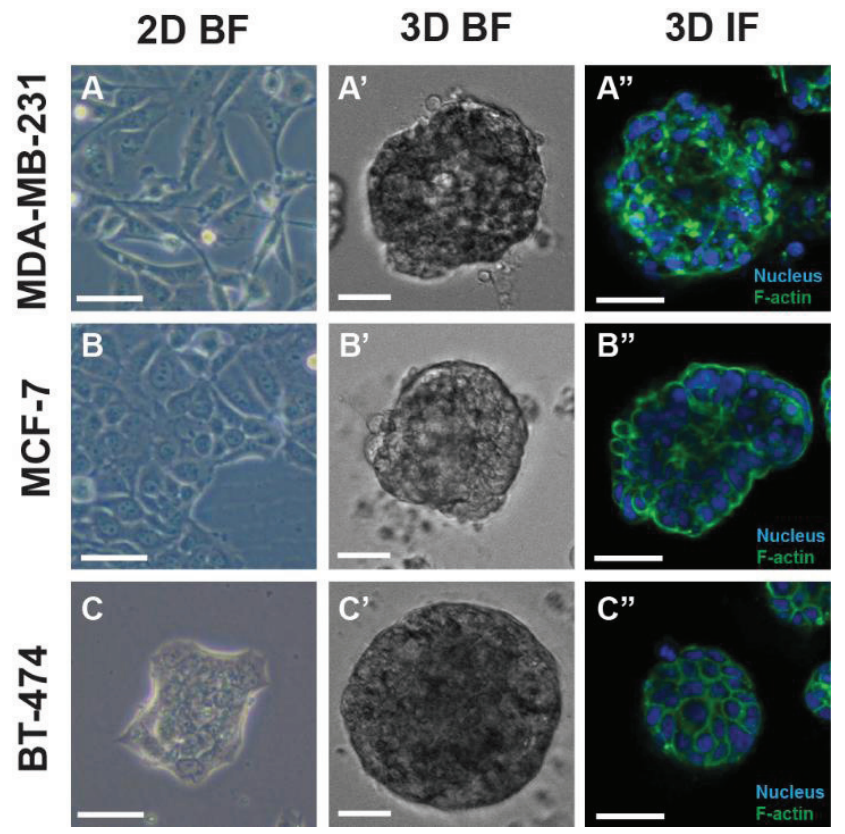

In addition to the anchorage-independent model, the formation of anchorage-dependent 3D cell structures resulting from cells adhering to specific substrates have been developed. One of these specialized substrates is comprised of a membrane, and the resultant structures are commonly referred to as multilayered cell cultures (MCCs). MCCs are composed of tumor cells cultured on a membrane and are specifically designed to allow measurement of drug diffusion [15,16]. Microfluidics channels which employ micropillars are also able to support the formation of 3D cell cultures and, in addition, ECM can also be added into these chambers to allow ECM-to-cell interactions [17]. Basement membrane extract from the Engelbreth-Holm-Swarm murine tumor, a form of laminin-rich ECM (1rECM), has been extensively utilized to promote the growth of cancer cells in 3D structures [18-21]. In addition to cancer research, $1 \mathrm{rECM}$ has been employed as a biologically relevant scaffold for the elucidation of in vivo functional processes of non-malignant tissue in vitro [22-25]. The methods for culturing cells in $3 \mathrm{D}$ utilizing $1 \mathrm{rECM}$ as a subtrate involves seeding a single cell suspension either on top of matrices (3D 'on top' assay) or mixed into 1rECM (3D 'embedded' assay), which promotes the formation of cells into 3D structures in a time-dependent manner [26]. LrECM is not the only biologically relevant matrix available for 3D cell culture. Collagen I has also been utilized as a substrate for culturing tumor cells in 3D systems [27]. Malignant cells cultured in 3D utilizing lrECM as a substrate display distinctive morphologies [28,29], which is in contrast to the more uniform cellular aggregation observed in anchorage-independent 3D cell culture [7,30]. There are advantages and disadvantages associated with utilizing either anchorage-dependent or anchorage-independent 3D tumor models, which have been reviewed in detail elsewhere [31]. 


\section{Drug Resistance and 3D Tumor Models}

Drug resistance in cancer can be mediated by two different mechanisms, namely acquired and de novo. Acquired resistance results from modifications which occur during exposure of tumors to therapeutics and de novo resistance is associated with factors, such as adhesion of tumor cells to ECM, that existed prior to therapy [32,33]. The resistance mechanisms implicated in reducing drug effectiveness when the cancer patient is undergoing therapy include non-specific mechanisms, such as increased drug efflux from tumor cells, specific cellular processes of down-regulation or up-regulation of a drug target, the presence of cancer stem cells and the influence of tumor microenvironmental components [34]. Research suggests that solid tumors adapt quickly to treatment with chemotherapeutics, with genomic alterations detected shortly after cellular exposure to drugs [35]. A number of factors affecting the activity of anti-cancer drugs in vivo are able to be recreated in vitro utilizing 3D cell culture models [36]. The advantages of exploiting cells grown in 3D culture conditions in comparison to $2 \mathrm{D}$ culture models for evaluating drug candidates and exploring mechanistic properties of anti-cancer agents can include: (i) oxygen and nutrient gradients, (ii) increased cell-to-cell interactions resulting from cellular formation into 3D architecture, (iii) non-uniform exposure of cells within a spheroid to drug/compound, (iv) ECM-to-cell signaling, (v) different rates of cellular proliferation throughout the 3D structure and, (vi) impact of stromal/tumor site specific cells in the tumor microenvironment (Figure 2).

Figure 2. Advantages of incorporating elements of the tumor microenvironment in drug discovery programmes.

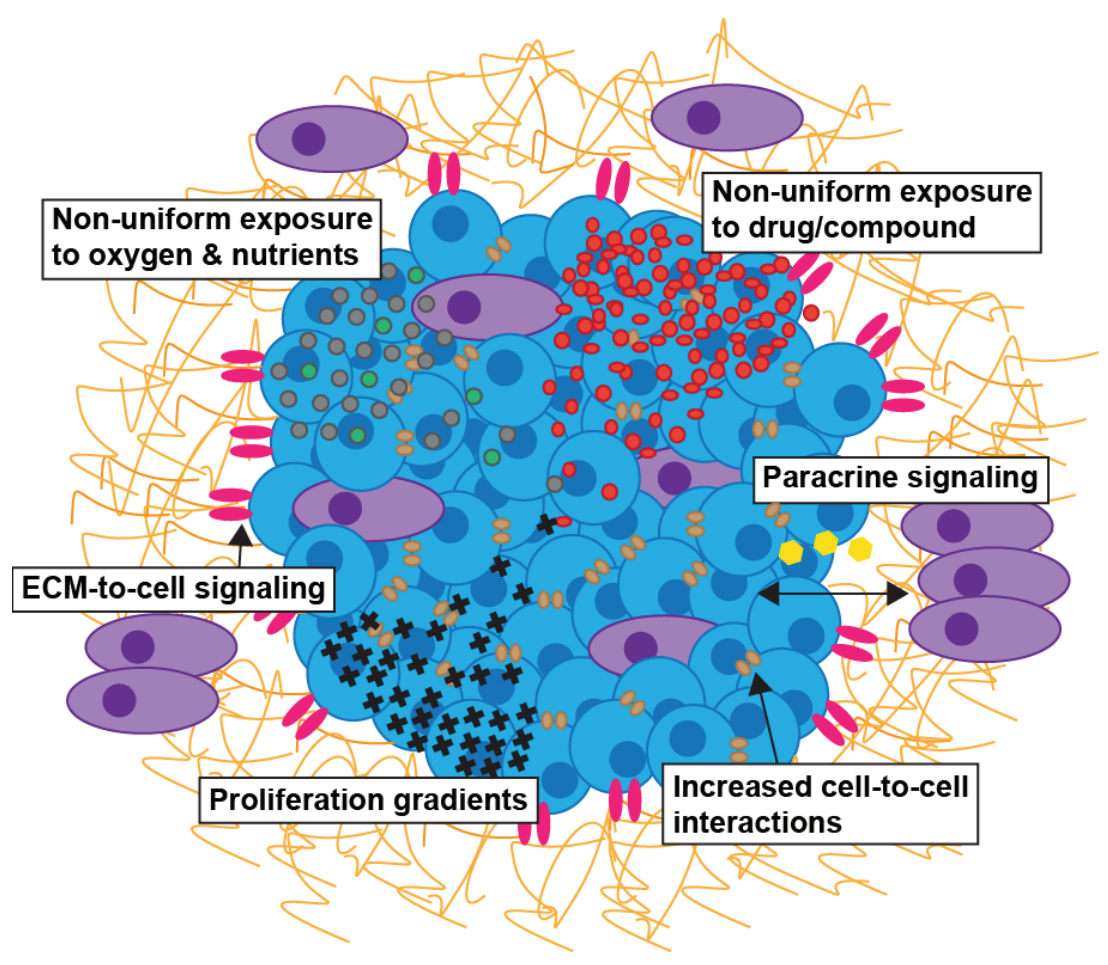

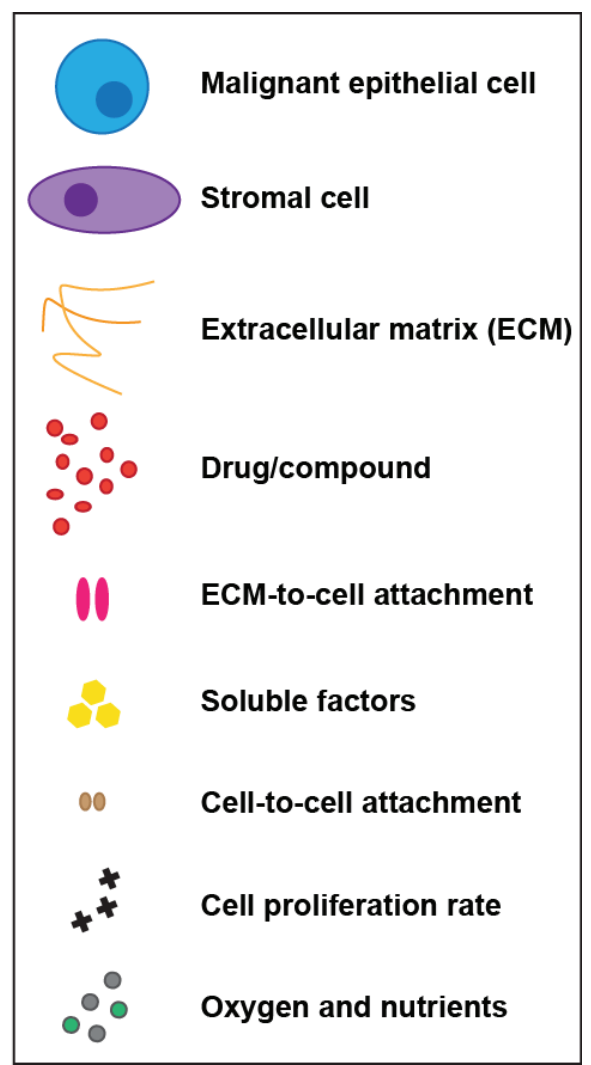


Numerous anti-cancer therapeutics have been evaluated in a range of different cancer cell types in $3 \mathrm{D}$ cell culture systems and directly compared to the same cells grown in a 2D monolayer format. Studies have have shown that tumor cells were less sensitive to anti-cancer agents when evaulated in a $3 \mathrm{D}$ system compared to 2D culture conditions [37-39]. However, there has also been a number of studies where the observed effects of anti-cancer agents against tumor cells in $3 \mathrm{D}$ culture were equal to, or more sensitive to, the same tumor cell type cultured in a $2 \mathrm{D}$ monolayer format [40-42]. The information acquired from employing these $3 \mathrm{D}$ cell cultures in cancer research, irrespective of whether the cellular sensitivity to drugs/compounds is increased or decreased, has the potential to provide a more accurate representation of drug/compound activity in vivo. For instance, if the drug/compound sensitivity is decreased in tumor cells cultured in a 3D model, what mechanism/s of resistance are in play and how could these parameters affect the anti-tumor action of the drug/compound in vivo? Alternatively, if drug/compound sensitivity against tumor cells is increased in $3 \mathrm{D}$ cultures, is there a greater dependence on the target in the 3D cellular system? Or, are there indirect influences on drug/compound activity in tumor cells propagated in 3D culture not observed against cells cultured in 2D monolayers? The development of more advanced 3D cell culture models, such as those incorporating components from the tumor microenvironment, will be valuable in deconstructing these mechanistic elements.

\section{Cellular Signaling in 3D Tumor Models}

Culturing cells in 3D was envisaged decades ago as having potential for use in functional studies of malignant and/or non-malignant tissue [22,43-46]. In more recent years, an explosion of new techniques and the extensive characterization of a wide range of cancer cell lines has given researchers the opportunity to dissect cellular pathways in these more biologically relevant models and, in some instances, make comparative assessments to cells in traditional 2D monolayer culture. If pathways of cells in 2D models are not representative of the in vivo microenvironment, then screening for active compounds utilizing these models may not be as predictive. For example, the cellular target of a particular compound may not be expressed in the same quantities in vivo or the cellular signaling occuring in vivo may not be reflected in cells grown as $2 \mathrm{D}$ monolayers and therefore impact on the outcome.

A significant volume of research into molecular alterations of cells has been performed utilizing 3D cancer models, including examination of the genetic variations between different cell culture conditions. In one study, the gene expression of a panel of 24 malignant and non-malignant breast cell lines was compared between 2D monolayer cultures and 3D cell cultures generated on 1rECM [28]. Significant modifications in gene expression were detected for genes encoding signal transduction proteins across the panel of cell lines tested, which provides supporting evidence that cellular signaling is altered in 3D cell cultures established on 1rECM. In addition, changes in gene expression were also examined in a panel of malignant and non-malignant prostate cell lines [29]. In the 3D cell cultures of these cell lines, the gene expression patterns reflected the decreased cellular propagation upon culturing cells in 1rECM in comparison to that of cells in 2D monolayer culture. Furthermore, research into changes in gene expression occurring between 2D and 3D cell cultures has also been completed in melanoma cells. A study by Ghosh et al. [47] demonstrated that 106 genes were up-regulated and 73 
genes down-regulated in anchorage-independent 3D cell culture in comparison to the 2D monolayer cell cultures for the same cell line (NA8). The genetic alterations of interest included a number of chemokines (CXCL1, CXCL2 and CXCL3), IL-8 and CCL20 which were significantly up-regulated in cells cultured in 3D conditions.

Studies have also investigated specific alterations at the protein level of cells cultured in 3D systems. In a large panel of ovarian cancer cell lines, modifications in cell adhesion marker expression were observed, particularly for vimentin and E-cadherin, in 3D cell cultures when directly compared to 2D monolayer cell cultures [48]. In addition, a proteome analysis between 2D and 3D cell cultures of the colon cancer cell lines COGA-5 and COGA-12 was undertaken [49]. Results demonstrated alternative protein expression of certain proteins, for example, hydroxyprostaglandin dehydrogenase and lamin $\mathrm{A} / \mathrm{C}$ in GOGA-5 cells cultured as spheroids in comparison to the same cells grown in $2 \mathrm{D}$ monolayer cultures. A 3D co-culture model for prostate cancer was developed to evaluate interactions between prostate cancer cells and stromal cells derived from the bone [50]. The prostate cancer cell line, PC3, was co-cultured with the bone stromal cell line, HS5, in 3D cell cultures generated on 1rECM. In these co-cultures, cell-to-cell interactions and cross-talk between the different cell types was demonstrated, with the re-expression of CXCR7 and N-cadherin occuring in HS5 cells. Furthermore, $\alpha 6$ - and/or $\beta 1$-integrins were shown to influence the expression of certain cellular components, for example, E-cadherin and vimentin not only in 3D co-culture conditions, but also in mono-culture of PC3 and HS5 cells. It is evident that culturing cells in 3D alters gene and protein expression, however, it is yet to be determined if any of the changes observed between in tumor cells of 2D and 3D cell cultures will lead to identification of novel drug targets and if the changes in expression alone can influence the sensitivity of anti-cancer drugs.

The presence of ECM in the tumor microenvironment has been proven to effect drug activity against a variety of cancer cells. Numerous studies, in a range of different cancer cell lines, have shown that cancer cells cultured in 2D monolayers in the presence of different components of ECM proteins have reduced sensitivity to anti-cancer agents. For instance, in the breast cancer cell line MDA-MB-231, adhesion of $\alpha 5 \beta 1$ - and $\alpha 2 \beta 1$-integrin to fibronectin and collagen I, respectively, was protective against paclitaxel cytotoxicity [51]. In lung cancer, a panel of cell lines (H69, H345 and H510) were cultured on either collagen IV, laminin or fibronectin and exposed to doxorubicin, cyclophosphamide or etiposide, with cellular attachment to all substrates resulting in increased cellular viability upon application of these apoptotic stimuli [52]. Furthermore, pancreatic cancer cells (AsPc-1) cultured on laminin were partially protected from gemcitabine, with the signaling of focal adhesion kinase (FAK) demonstrated to be a contributing factor [53]. Cellular adhesion to ECM has also affected the sensitivity of anti-cancer agents on cells in 2D monolayer culture of prostate cancer [54] and glioblastoma cells [55]. Thus, attachment of tumor cells to specific ECM proteins affect the response of a wide range of cancer cells to therapeutics in 2D monolayer cell culture.

The 3D architecture of spheroids, in addition to the presence of ECM proteins in cell culture models, affect cellular responses to chemotherapeutic drugs. A study undertaken by Hakanson et al. [56] demonstrated this concept, revealing that a small 3D structure (less than 6 cells per aggregate) consisting of MCF-7 breast cancer cells was more resistant to paclitaxel in the presence of ECM proteins when compared to the same cells cultured in 2D on a layer of identical ECM proteins. Spheroid models have been ulilized to evaulate tumor cell signaling in comparison to 2D monolayer 
cultures in various cell lines. Notably, signaling downstream from human epidermal growth factor receptor type (Her2) was altered when cancer cells were cultured in anchorage-independent 3D conditions in comparison to a 2D monolayer format [42]. Specifically, a switch from the phosphoinositide 3-kinase (PI3K) pathway to the mitogen activated kinase (MAPK) pathway was demonstrated in breast, lung and ovarian cancer cell lines. The cell culture condition-dependent pathway switch was also observed in a study undertaken by Weigelt et al. [57] using breast cancer cell lines cultured in an lrECM-based model.

Studies into the activity of anti-cancer agents against cells cultured as anchorage-independent spheroids have been performed. Mesothelioma cancer cell lines (M28, REN and VAMT) cultured in both $2 \mathrm{D}$ culture and a 3D anchorage-independent cell culture format exhibited resistance in the 3D system in response to application of apoptotic stimuli [39]. Certain proteins from the PI3K pathway were identified as having a role in mediating the observed resistance. Furthermore, decreased doxorubicin activity was detected in selected endometrial cancer cell lines cultured as anchorage-independent spheroids in comparison to the same cells cultured in 2D monolayers [58]. The enhanced resistance was potentially associated with cell line-dependent mechanisms including altered signaling through the PI3K pathway and altered antioxidant protein presence. Variations in drug activity against cells cultured as anchorage-independent spheroids compared to the same cells grown in $2 \mathrm{D}$ monolayer cultures is not unique to the types of cancer mentioned above. Altered drug sensitivity in cells cultured as anchorage-independent spheroids compared to cells cultured in a monolayer has also been observed in bladder [59], pancreatic [60,61] and colon cancer [62].

Altered signaling and sensitivity to anti-cancer agents was also observed in cell lines when cultured as $3 \mathrm{D}$ structures using $1 \mathrm{rECM}$ as a substrate. The susceptibility of breast cancer cell lines over-expressing Her2 (AU565, SKBR3, HCC1569) to therapeutics targeting Her2 signaling (trastuzumab, pertuzumab and lapatinib) was cell line-, cell culture condition (2D vs. 3D)- and drug-dependent [57]. For instance, SKBR3 cells were significantly more resistant, AU565 cells were significantly less resistant and HCC1569 cells displayed an equivalent activity profile to trastuzumab in 3D cell culture in comparison to $2 \mathrm{D}$ monolayer cell culture. Furthermore, the results from this study also demonstrated the influence of the surrounding ECM microenvironment on the response of cells in 3D cultures to the Her2-targeted therapies by showing the combination of a $\beta 1$-integrin inhibitor with each anti-Her2 agent generally enhanced the anti-tumor activity.

3D modeling employing lrECM in the culture microenvironment has provided a unique tool for use in the elucidation of cellular signaling mediated by integrins. An early study demonstrated that inhibiting the function of $\beta 1$-integrin in breast cancer cells (T4-2) cultured in 3D conditions triggered a reversion of these cultures to a non-malignant phenotype [18]. In the same study, $\alpha 6$ - and $\beta 4$-integrin function was inhibited in a 3D cultured non-malignant breast cancer cell line (S-1), and following treatment, these cultures exhibited features observed in malignant phenotype. Further research demonstrated that the phenotype of multiple breast cancer cells showed at least a partial morphological reversion to a normal tissue architecture when exposed to a number of specific inhibitors applied in combination or as single agents, for example, those targeting MAPK and/or $\beta 1$-integrin [63]. Additionally, research was conducted into the influence of integrin binding on the formation of 3D structures. A synthetic hydrogel consisting of RGD binding sites was utilized, with results demonstrating enhanced growth of ovarian cancer cells upon integrin attachment to the substrate [64]. 
$\beta 1$-integrin was also explored as a potential drug target utilizing 3D cell culture models situated in an 1rECM-containing microenvironment. Blocking the function of $\beta 1$-integrin in breast cancer cell (T4-2, MDA-MB-231, BT-474, MCF-7 and SKBR3) cultured as pre-formed 3D structures successfully inhibited the growth of these malignant cells [19] and enhanced the anti-cancer affects of breast cancer cells (MCF-7 and T4-2) following exposure to ionizing radiation [65].

The investigation of resistance against anti-Her2 therapeutics in breast cancer cell lines revealed that $\beta 1$-integrin downstream signaling has a role in mediating this altered sensitivity $[66,67]$. $\beta 1$-integrin was also demonstrated to be protective against several anti-cancer agents in hepatoma cells [68]. Furthermore, attachment of cells to $1 \mathrm{rECM}$ was shown to protect cells from apoptosis in ovarian cancer $3 \mathrm{D}$ cultures upon exposure to the $\mathrm{PI} 3 \mathrm{~K} /$ the mammalian target of rapamycin (mTOR) inhibitor, BEZ235 [20]. The altered drug sensitivity was attributed to the up-regulation of pathways specific to cellular survival. Targeting the pro-survival protein, Bcl-2, insulin growth factor type 1 receptor (IGF1R) or epidermal growth factor receptor (EGFR) in combination with BEZ235 abolished the resistance observed with matrix-attached cells. Therefore, the presence of ECM is an important factor when considering the efficacy of therapeutics in the in vitro $3 \mathrm{D}$ tumor microenvironment.

Together, these studies highlight the differing genetic profiles, protein expression and drug sensitivity, which are evident in cells cultured in the more physiologically relevant $3 \mathrm{D}$ cell culture models compared to traditional 2D cell culture models. These studies also emphasize the importance of using 3D cell cultures to complete mechanistic studies on current chemotherapeutics and novel drug candidates. An awareness of the differences, sometimes significant, between cells cultured in 2D and 3D is an important factor when considering which model to select for the screening of new molecular entities. The benefits of screening biologically active compounds against cells in 3D culture models is their ability to account for these changes e.g., the switch in PI3K pathway signaling to MAPK pathway signaling observed in $3 \mathrm{D}$ cancer cell cultures, but not in 2D monolayer cell cultures as mentioned above $[42,57]$. The challenge is to incorporate the essential elements of these models into early-stage drug discovery practices.

\section{Utilizing 3D Tumor Models in Drug Discovery: Progress So Far}

The development and use of 3D cell cultures in drug discovery is becoming more prevalent. At the present time, a collaboration of academic laboratories and pharmaceutical/biotechnology companies in Europe has been established to develop new, more relevant, in vitro models for drug discovery practices [69]. Numerous methodologies have been established for novel compound screening practices utilizing 3D cell culture systems in cancer, particularly within the last few years. These procedures have included both non-adherent 3D cell cultures (anchorage-independent) and 3D structures which adhere to a substrate (anchorage-dependent). The assays have not only been developed by pharmaceutical companies, but also academic laboratories (Table 1). Below, we describe the outcomes from published assays that have been established and utilized in the screening of either a library of compounds/clincally relevant drugs or a small panel of reference drugs. 
Table 1. Three-dimensional cell culture amenable assay technologies.

\begin{tabular}{|c|c|c|}
\hline Assay Chemistry and Endpoint & Commercial Products & Reference \\
\hline \multicolumn{3}{|c|}{ Microscopy (object-based) } \\
\hline \multicolumn{3}{|l|}{ Cell Viability } \\
\hline Live/dead cell staining assay & $\begin{array}{l}\text { LIVE/DEAD } \\
\text { Viability/Cytotoxicity Kit }\end{array}$ & {$[70]$} \\
\hline Live cell staining assay & Calcein AM dye & {$[21]$} \\
\hline Live/dead cell staining assay & Hoechst and Sytox Green dyes & [71] \\
\hline \multicolumn{3}{|l|}{ Invasiveness } \\
\hline Brightfield & & {$[5,29]$} \\
\hline \multicolumn{3}{|l|}{ Spheroid Size Analysis } \\
\hline Brightfield & & {$[5,29,72]$} \\
\hline \multicolumn{3}{|l|}{ Colony Count and Size } \\
\hline Qdots/Calcein AM & Qtracker ${ }^{\circledR} 625$ Cell Labeling Kit & [73] \\
\hline \multicolumn{3}{|l|}{ Architectural Disruption of 3D Cell Cultures } \\
\hline Live/dead cell staining assay & $\begin{array}{l}\text { LIVE/DEAD } \\
\text { Viability/Cytotoxicity Kit }\end{array}$ & {$[70]$} \\
\hline \multicolumn{3}{|c|}{ Plate Reader (whole-well) } \\
\hline \multicolumn{3}{|l|}{ Cell Viability } \\
\hline Tetrazolium reduction assays (MTT, MTS) & $\begin{array}{l}\text { CellTiter } 96^{\circledR} \text { AQueous One } \\
\text { Solution Cell Proliferation } \\
\text { Assay (MTS) }\end{array}$ & {$[27]$} \\
\hline Resazurin reduction assay & $\begin{array}{l}\text { alamarBlue }{ }^{\circledR} \text { cell viability } \\
\text { reagent, CellTiter-Blue }{ }^{\circledR} \text { Cell } \\
\text { Viability Assay, Resazurin } \\
\text { sodium salt }\end{array}$ & {$[8,21,74,75]$} \\
\hline ATP measurement assay & $\begin{array}{l}\text { CellTiter-Glo }{ }^{\circledR} \text { Luminescent } \\
\text { Cell Viability Assay }\end{array}$ & {$[5,76]$} \\
\hline Acidic phosphatase (APH) assay & & {$[77,78]$} \\
\hline \multicolumn{3}{|l|}{ Apoptosis Assessment } \\
\hline ELISA (caspase-cleaved CK18 fragments) & M30 Apoptosense ${ }^{\circledR}$ ELISA & [79] \\
\hline \multicolumn{3}{|l|}{$\begin{array}{l}\text { Epithelial-to-Mesenchymal Transition Related } \\
\text { Protein Expression }\end{array}$} \\
\hline Luminescent reporter protein & & {$[78]$} \\
\hline
\end{tabular}

\subsection{Anchorage-Dependent 3D Tumor Models Developed for Use in Drug Discovery Programmes}

\subsubsection{Breast, Pancreatic and Ovarian Cancer}

Numerous anchorage-dependent models for drug discovery have been developed. Recently, we developed miniaturized 3D cell culture assays utilizing small panels of both breast (MCF-7, MDA-MB-231 and BT-474) and pancreatic (Panc-1, AsPc-1 and BxPc-3) cancer cell lines, suitable for use in drug discovery programmes [21]. The assays established were based on 3D cellular structures situated on 1rECM in a 384-well microtitre plate format, a configuration compatible with a range of liquid handling, imaging and multilabel plate reading equipment. A pilot screen was conducted using a 
small library of 741 clinically relevant drugs and compounds, initially measuring cellular activity in 2D monolayer cell cultures, followed by re-testing of active anti-cancer agents against cells in both 2D and 3D cell culture models. The outcomes included the identification of 10 drugs displaying anti-cancer activity on the above-mentioned cells, with one drug, an anti-parasitic (maduramicin ammonium) not previously reported as exhibiting cytotoxic activity against cancer cells. The remaining drugs that demonstrated anti-cancer activity against selected breast and pancreatic cancer cell lines in the screen included statins, an immunosuppressant, an iron chelator and a cardiac glyoside. The drugs identified and subsequently characterized in this study exhibited activity against cells in both $2 \mathrm{D}$ and $3 \mathrm{D}$ cell cultures, however, the cellular response to a number of these drugs was model-dependent.

An anchorage-dependent 3D cell culture model utilizing $1 \mathrm{rECM}$ as a scaffold, an anchorage-independent model utilizing poly-HEMA to induce spheroid formation and a 2D monolayer cell culture model were employed to test a library of 102 drugs and compounds against the JIMT1 breast cancer cell line (over-expresses Her2) in a 384-well microtitre plate format [76]. Sixty-three drugs/compounds exhibited greater than a $30 \%$ reduction in cell viability in one or more of the above-mentioned models. However, a large difference in drug/compound activity was observed between cells cultured in these different models. For example, colchicine, a drug used for the treatment of gout, inhibited cells cultured in the 2D monolayer and the 3D 1rECM format to a greater capacity than observed for cells cultured in the anchorage-independent model. Interestingly, the gene expression of cells cultured in the 3D 1rECM model was shown to more closely resemble the in vivo situation.

A high-content approach to the quantitative assessment of $3 \mathrm{D}$ tumor models utilizing a Matrigel-based 1rECM model was developed. In this study, pancreatic (Panc-1) and ovarian (NIH:OVCAR-5) cancer cell lines were cultured in 96-well microtitre plates and 5 clinically relevant cytotoxic compounds were used to validate the system [70]. The study looked at streamlining the methodology and analysis of high-content 3D cell culture models while maintaining the screening speed traditionally achieved in whole-well reporter assays. Multiple assessment endpoints were measured from the cultures exposed to treatments including cell viability-based on cytotoxicity and growth inhibition in addition to structure and size-dependent responses. The system presented can be incorporated into laboratories with standard imaging and computer equipment while producing multiple quantitative readouts.

\subsubsection{Prostate Cancer}

Krausz et al. [72] recently published anchorage-dependent 3D cell culture assay methodology for prostate cancer, which is suitable for high-content screening (HCS) (96-well microtitre plate format). Initially, comparisons of various imaging platforms (MIAS- ${ }^{\circledR}$, IN Cell Analyzer $2000^{\circledR}$ and an Opera $^{\circledR}$ ) and their respective analysis programs along with their in house tool, Plate-based HighContent Analysis Evaluation and Dynamic Reliability Assurance (Phaedra) were performed. There were no major differences reported between data obtained from the imaging and analysis of cells in 3D structures for all of the instruments utilized. Next, a 3D co-culture assay was developed consisting of bone marrow stromal cells with prostate (PC3-M) tumor cells situated in 1rECM. Anti-cancer agents, including topoisomerase I, mitogen-activated protein kinase kinase (MEK-1/2), SRC kinase and 
histone deacetylase inhibitors were evaluated, with reproducible data acquired. In a separate study, more than 100 compounds were screened against prostate cancer PC3 and PC3-M cells in a 3D cell culture system which utilized an $1 \mathrm{rECM}$ framework in addition to a corresponding 2D cell culture assay (384-well microtitre plate format) [29]. The compounds demonstrating anti-cancer activity on these cell lines were further tested on a panel of prostate cancer cell lines (EP156T, RWPE-1, DU145, LNCaP and 22rV1) in 3D cell culture. The findings from this study included the identification of compounds that targeted PI3K pathway signaling in cells. These compounds inhibited the invasive properties of tumor cells cultured in $3 \mathrm{D}$, yet demonstrated reduced efficacy against cells in corresponding 2D monolayer cell culture. Alternatively, the majority of inhibitors targeting mTOR and IGF1R signal transduction were effective against malignant and non-malignant cell lines cultured as both monolayers and 3D structures. Thus, the target of the compound would appear to dictate whether the cellular response is dependent on the cell culture conditions utilized.

\subsubsection{Lung Cancer}

Differences in the susceptibility of cells to anti-cancer agents in alternative cell culture systems has been reported for the lung cancer cell lines, A549 and H358 [27]. These cell lines were cultured as 3D structures within a collagen I matrix in a 96-well microtitre plate and in a corresponding 2D monolayer cell culture assay format. The outcomes from this study demonstrated that the cellular sensitivity to the anti-cancer agents was cell line-, drug- and culture method-dependent. For instance, in the A549 cell line, the potency of alimta, zactima, and gemcitabine were significantly higher, whilst paclitaxel, KU174, doxorubicin and vinorelbine were significantly lower in cells cultured in 3D in comparison to cells cultured in 2D. The activities of cisplatin, 17AAg and KU363 were comparable against cells cultured in both $2 \mathrm{D}$ and $3 \mathrm{D}$ assays. The presence of a collagen I framework therefore influences drug sensitivity, whether the effects be dependent on the 3D cellular architecture or ECM-to-cell signaling.

Collagen I and lrECM have been utilized as support networks for the culture of 3D cellular structures, whether for mono-culture or co-culture, in microtitre plates including both 96- and 384-well formats for a wide range of cancers. Anchorage-dependent assays developed for use in drug discovery platforms have either been validated through the screening of biologically active drugs/compounds or a small panel of chemotherapeutic agents, with a substantial volume of results demonstrating the altered senstivity of cells to drugs/compounds when cultured in a 3D architecture with substrata.

\subsection{Anchorage-Independent 3D Tumor Models Established for Evaluation of New Molecular Entities}

\subsubsection{Brain, Breast and Oral Cancer}

In addition to the anchorage-dependent 3D models, a range of anchorage-independent assays suitable for screening practices have also been developed. For instance, several different inhibitors including heat shock protein 90 (17-N-allylamino-17-demthoxy-geldanomycin; 17AAG), PI3K/mTOR (PI-103) and phospholipase C (CCT130234) were evaluated in numerous cancer cell lines (glioblastoma: U-87 MG, KNS42; breast cancer: MDA-MB-231 and oral squamous cell carcinoma: LICR-LON-HN4) utilizing an anchorage-independent 3D cell culture assay in a 96-well format [5]. Following exposure to the various inhibitors, cellular viability was demonstrated to be approximately 
equal to, or higher, when 2D monolayer cell culture was compared to 3D cell culture spheroids. This anchorage-independent assay methodology could also be extended to measure the migration and invasion of tumor cells upon treatment. Whilst these assays have not been utilized for the screening of novel compounds, the above-mentioned anti-cancer agents were used to exemplify the inhibitory actions of these therapeutics against cells on the different 3D cell culture platforms.

In a study also utilizing the breast cancer cell line, MDA-MB-231, an epithelial-to-mesenchymal transistion (EMT) anchorage-independent spheroid model (96-well microtitre plate format) was developed by incorporating a luciferase reporter of EMT in cells [78]. Two-hundred and thirty compounds were screened and their activity against MDA-MB-231 cells determined in luminescence and cellular viability assays. Four compounds that selectively inhibited EMT were identified: mycalolide $\mathrm{E}$ and jaspamide, which both target F-actin; and isonaamidine $\mathrm{B}$ and papuamine, which have unknown modes of action. In a separate breast cancer study, a HCS assay was established in a 384-well microtitre plate format using the breast cancer cell line, TD74, cultured as MCTS to specifically detect compounds that target dormant cells located within the spheroid interior [71]. Following the screening of 1120 compounds, 9 respiratory chain inhibitors targeting these quiescent cells were identified. A unique 3D cell culture model allowed selective detection of the inhibition of EMT in conjunction with cellular viability and, in addition, 3D cell culture methodology facilitated the detection of inhibitors specifically targeting dormant cells.

\subsubsection{Pancreatic Cancer}

A panel of pancreatic cell lines (AsPc-1, BxPc-3, Capan-1 and Panc-1) were utilized in an anchorage-independent assay developed into a 96-well microtitre plate using methylcellulose as a cell-repellant to stimulate spheroid formation [77]. Eleven compounds with a range of targets, for example, microtubulin, were examined. The outcomes included compounds (MT100, Allicin and AXP-107-11) which exhibited activity against cells grown in both 2D and 3D conditions. However, the majority of compounds (H107, CB5, CB7, CB13, 6-MP, 6-MPR, act16412 and GANT61) generally demonstrated modest activity against cells cultured in $2 \mathrm{D}$, but only limited activity against cells grown in 3D culture. Thus, the cells cultured in this 3D model frequently demonstrated reduced sensitivity to a range of compounds when compared to the same cells cultured in 2D monolayer conditions. The differences in compound activity against cells in these culture systems may have been mediated by the more chemoresistant phenotype of spheroids observed in this study, for example, the increased amount of ECM proteins present in these 3D cell cultures.

\subsubsection{Lung and Colon Cancer}

A soft agar colony formation assay was established in a 384-well microtitre plate format for the lung cancer cell line HCC827 [75]. A library of 9600 compounds was tested against these cells cultured in both a 2D monolayer and 3D formats. The majority of active compounds (unknown targets) exhibited similar activity against cells irrespective of whether cultured in 2D or 3D conditions. This assay demonstrated the development of the first published soft agar assay in a 384-well microtitre plate format and the successful screening of a library of compounds. Horman et al. [73] adapted this soft agar colony formation assay to screen colon cancer cells (HCT116) which were cultured with and 
without normal colon fibroblasts (CCD-18Co). The 3D mono-culture assay was utilized in the testing of a library of 1528 compounds derived from natural sources. The criteria for selecting active compounds was at least a $60 \%$ reduction in growth of mono-cultured cells in $3 \mathrm{D}$ structures. The 83 active compounds were re-tested against cells in the $3 \mathrm{D}$ co-culture model, with a re-confirmation rate of approximately $50 \%$. Thirty compounds were active against these HCT116 cells with an $\mathrm{IC}_{50}$ below $1 \mu \mathrm{M}$. Interestingly, a selection of compounds demonstrated increased activity against the colon cancer cells in comparison to the normal fibroblasts and, in addition, certain compounds inhibited the growth of only the cells tested in 3D cultures, not 2D monolayers. These results emphasize the importance of assessing compounds against cellular activity in 3D culture models, as active compounds may have remained undiscovered when applied to cells in standard 2D monolayer systems.

An anchorage-independent 3D lung cancer model which utilized Algimatrix ${ }^{\mathrm{TM}}$ as a scaffold was developed for use in screening practices [74]. Lung cancer cells (H460, A549, H1650 and H1650 stem cells) in both 2D and 3D cell culture systems were tested against a small panel of chemotherapeutics including docetaxel, cisplatin, gemcitabine, 5-fluorouracil and camptothecin. The outcome of this study showed that cells cultured in 3D were more resistant (5-20 fold) across the entire panel of drugs when compared to cells cultured in 2D conditions, with the stem cell enriched culture exhibiting greater resistance than the parental cell line (H1650). These results show the use of a chemically defined scaffold to culture cells $3 \mathrm{D}$ and its potential for use in evaluating the activity of anti-cancer agents.

The colon cancer cell line (HCT116) was also employed in an additional anchorage-independent 3D cell culture assay (96-well microtitre plate format) [79]. This assay was established to identify compounds that specifically trigger cellular apoptosis. A library containing a collection of 77 compounds and anti-cancer drugs were screened against these HCT116 cell line-containing spheroids, with numerous drugs/compounds shown to induce apoptosis. However, the ability of these drugs/compounds to instigate apoptosis was dependent on whether the colon cancer cells were cultured in 2D monolayers or 3D in culture. For instance, tamoxifen was demonstrated to trigger apoptosis in cells cultured in both types of models, but in contrast, cisplatin showed enhanced activity against cells in $2 \mathrm{D}$ culture in comparison to the same cells cultured in 3D. Thus, this research shows the development and assessment of an anchorage-independent spheroid assay for apoptosis endpoint detection and illustrates the capabilities of the assay with established anti-cancer agents.

\subsubsection{Epidermoid Cancer}

An epidermoid cancer cell line over-expressing mesothelin (A431.H9) was used in the development of a high-throughput hanging drop assay in a 384-well format, with cellular viability measured with alamarBlue [8]. The differing sensitivities of cell in 3D cell cultures were demonstrated utilizing the two drugs of tirapazamine (cellular inhibitor which causes DNA damage; demonstrates enhanced activity in the presence of hypoxia) and 5-fluorouracil (blocks the propagation of cells). Cells cultured in $3 \mathrm{D}$ exhibited resistance in comparison to the same cells cultured in 2D monolayers upon exposure to 5-fluorouracil. However, when tirapazamine was applied, the cells grown in 3D culture demonstrated increased sensitivity in contrast to those cultivated in 2D monolayer culture. These distinct responses were attributed to the altered properties of cellular activity in $3 \mathrm{D}$ conditions in comparison to that of 
cells in 2D monolayers. This study demonstrates the development and evaluation of a hanging drop assay which utilizes a 384 hanging drop array plate suitable for integration into HTS platforms.

Collectively, numerous 3D cell culture assays have been developed and represent progress towards recapitulating the complete tumor microenvironment in comparison to utilizing only traditional $2 \mathrm{D}$ monolayer cell culture models for the screening of drug candidates. The inclusion of certain tumor components in addition to cells cultured in $3 \mathrm{D}$ conditions has contributed to successfully identifying differences in the anti-cancer activity of compounds/drugs in selected screens. However, there is still a significant amount of research required to establish 3D cell culture assays that not only possess the essential elements of a tumor in a panel of cancer cell types, but are automated and analyzed in a high-throughput manner.

\section{Towards More Complex Assays Suitable for Integration in Drug Discovery Programmes}

Screening programs rely on various forms of technology for determining the anti-cancer activity of compounds. The bottleneck for incorporation of more complex model systems into future drug screening is not only in tissue engineering and developing improved materials that reproduce optimal in vivo-like biological conditions, but also with the ability to apply these approaches in a drug discovery setting. An increasing number of companies are developing and manufacturing substrates, assay plates and scaffolds for the formation of 3D structures (for details see [31,80]). The increase in commercial interest in 3D cell-based technologies also applies to hardware and software aimed at this evolving industry.

To increase the throughput of compound screening in 3D cell culture, assays are required to be compatible with robotic systems including liquid handling technologies, which are generally in a 96- to 1536-well microtitre plate format. The use of these robotics allows accurate aspiration and dispensing of assay reagents and drug/compound in a timely manner. However, these liquid handling technologies, along with the data acquisition equipment, data analysis software packages and data storage/processing systems suitable for high-throughput applications have traditionally been expensive and not accessable to all laboratories. However, as access to high-throughput equipment such as liquid handling robotics and HCS platforms continues to become more viable, the integration of complex biological low-throughput models into formats suitable for the screening of compounds may be possible.

In recent years technical advances in imaging based technology has allowed for HCS based assays to be used in a number of 3D applications. Only recently has the computing power required to acquire and analyze large Z-stack data sets (critical for 3D cell culture) become available as a mainstream commercial product. Software solutions for complex analysis of 3D data are now available both commercially and as open source (Imaris ${ }^{\circledR}$, Volocity ${ }^{\circledR}$, Fiji). Several of these programs consist of features which enable batch analysis of large data sets that are becoming readily accessible for most academic groups, and are relatively user friendly. In addition, various analysis protocols which focus on deconstructing elements of cells cultured in $3 \mathrm{D}$, such as morphological profiles and biomarkers, designed for low-throughput and HCS experiments have been developed and published $[72,81,82]$. Technological advances such as these may not only allow a broader scope of models to be developed, but may further encourage the incorporation of $3 \mathrm{D}$ models in the search for anti-cancer drug candidates in the drug discovery pipeline. 
Scientific advances have resulted in the development of novel 3D cell culture models. These advances are in the form of a multitude of approaches including microfluidics [83-85] and novel scaffold/hydrogel designs $[86,87]$. These models have the potential to reduce the cost of materials and allow integration of elements, such as perfusion, that are unable to be incorporated into other models. Characteristics such as nutrient, gas and drug diffusion rates, cell shear stresses and other microenvironmental conditions can be more accurately controlled in these systems [88]. This tissue engineering technology is particularly suitable for not only replicating tumor microenvironments but for high-throughput drug screening conditons.

Progress has been made in cell biology with the expansion of 3D cell culture models into 3D co-culture systems. 3D cancer co-culture models have been developed in both low-throughput [89-92] and high-throughput $[5,72,73]$ formats. However, at the present time, only cancer cells along with one other cell type (e.g., fibroblasts) have been incorporated into models suitable in screening new compounds in a high-throughput manner. 3D cell cultures have the ability to recapitulate certain biological aspects of tumors, with the physical properties of the ECM playing a key role in addition to ECM-to-cell signaling [93]. The rigidity of the tumor microenvironment is frequently increased in comparison to normal tissues [94]. The increase in stiffness of the ECM surrounding tumor cells has been demonstrated to alter tissue structure and augment growth [95]. These mechanical forces within the in vitro $3 \mathrm{D}$ structure are model-dependent and are not generally taken into consideration when screening new molecular entities.

In addition to the application of $3 \mathrm{D}$ cell cultures to advance in vitro cancer models, there are alternative model systems that possess complexity between in vitro $2 \mathrm{D}$ monolayer and in vivo cancer models. These include the utilization of ex vivo approaches such as tissue slices [96] and Hi-Spot/OrganDots (tissue extraction, separation and re-aggregation into structures that exhibit similarities to the tissue in question on a membrane substrate) [97,98]. The limitations of using explanted tissues include inconsistency of tissue sources and the restricted supply of rodent/human tissue [98]. Whilst these model systems are applicable for use within small-scale studies evaluating novel molecular entities, they are currently not suitable for incorporation into early-stage drug discovery practices that require examination of a range of potential anti-cancer agents in a high-throughput manner.

Personalized medicine based on patient-derived cells has the possiblity to significantly enhance anti-cancer treatment for targeted molecular therapies. However, the application of patient-derived tumor models has been mostly limited to low-throughput pre-clinical testing to date $[99,100]$. Commercial institutes, such as Oncotest, have developed 3D assays based on indirect patient-derived samples, which have been expanded through the utilization of mouse xenograft models. Culturing of primary cells from patients and standardization for use in drug screening programs is currently a technical challenge. However, a 3D tumor model system based on multiple patient-derived cells to be incorporated into early-stage drug discovery may be the future of personalized drug development programmes.

There is increasing information available detailing the advantages and disadvantages of using 3D tumor models in early-stage drug discovery practices. However, much of the signaling changes and drug efficacy data remain unvalidated in an in vivo model. There are numerous 3D cell culture models developed for examination of drugs/novel compounds, but which model is the most representive of a tumor for a particular cancer? In addition, which cell types from the tumor microenvironment are to be 
included in 3D cancer co-culture models? It remains to be seen which model/s will prove the most useful in drug discovery practices.

Another approach that may be applicable to the future of advanced screening models is the standardization of 3D tumor models. For instance, what is the optimal drug exposure period? How large (cell number, diameter) should 3D structures be prior to drug addition? Also, which model is the most appropriate for each particular cancer? There are specific conditions in certain cancers required for enabling development of the most in vivo-like model possible. For example, ovarian cancer requires mesothelial cells which line peritoneal surfaces (the most common location for metastatic growth) to better represent the metastatic disease [101]. These conditions are unique to ovarian cancer and would therefore not be applicable for use in advanced in vitro models for other cancers. The question is then raised regarding how effectively $3 \mathrm{D}$ cell culture models can really be standarized over a large range of cancers, which does not even begin take into account all the different stages of disease within each type of cancer and the diverse sites of metastases. Would it be best to create models as close to the tumor microenvironment as possible and set out to standardize other parameters such as length of cellular exposure to drug and the size of the 3D cultures? Or, perhaps attempt to develop a universal 3D cell culture method that encompasses the key elements of all cancers? Further studies to determine the most representative advanced 3D tumor microenvironment models for each type of cancer may allow researchers to determine which cancers types can and cannot be standarized for use in a specific type of model.

\section{Conclusions}

A clearer understanding of the complex mechanisms influencing the mode of action and efficacy of cancer therapeutics is essential to move closer towards the goal of eradicating cancer cells in the patient. Research into new 3D tumor models that more closely represent the tumor microenvironment in systems that are scalable to meet the requirements of screening practices is underway, with notable progress published recently. However, there currently lacks a consensus with respect to which model reflects the nature of the various tumor types and therefore should be utilized for screening practices. In addition, the current 3D cell culture models recapitulate certain elements of the cancer setting, however, numerous components are excluded for each type of 3D cell culture model. Further advances in technology, personalized medicine and model development will no doubt overcome these obstacles.

\section{Acknowledgments}

We thank Amy Jones and Sabine Fletcher for critical reading of the manuscript. This work was supported by an Australian Postgraduate Award and a Cancer Therapeutics CRC top-up scholarship for Carrie J. Lovitt and an Australian Postgraduate Award and Discovery Biology top-up scholarship for Todd B. Shelper.

\section{Conflicts of Interest}

The authors declare no conflict of interest. 


\section{References}

1. Smalley, K.S.M.; Lioni, M.; Noma, K.; Haass, N.; Herlyn, M. In vitro three-dimensional tumor microenvironment models for anticancer drug discovery. Expert Opin. Drug Discov. 2008, 3, 1-10.

2. Weigelt, B.; Garjar, C.M.; Bissell, M.J. The need for complex 3D culture models to unravel novel pathways and identify accurate biomarkers in breast cancer. Adv. Drug Deliv. Rev. 2014, 69-70C, 42-51.

3. Kola, I.; Landis, J. Can the pharmaceutical industry reduce attrition rates? Nat. Rev. Drug Discov. 2004, 3, 711-715.

4. Pampaloni, F.; Reynaud, E.G.; Stelzer, E.H. The third dimension bridges the gap between cell culture and live tissue. Nat. Rev. Mol. Cell Biol. 2007, 8, 839-845.

5. Vinci, M.; Gowan, S.; Boxall, F.; Patterson, L.; Zimmermann, M.; Court, W.; Lomas, C.; Mendiola, M.; Hardisson, D.; Eccles, S.A. Advances in establishment and analysis of three-dimensional tumour spheroid-based functional assays for target validation and drug evaluation. BMC Biol. 2012, 10, 29.

6. Ivascu, A.; Kubbies, M. Rapid generation of single-tumor spheroids for high-throughput cell function and toxicity analysis. J. Biomol. Screen. 2006, 11, 922-932.

7. Friedrich, J.; Seidel, C.; Ebner, R.; Kunz-Schughart, L.A. Spheroid-based drug screen: Considerations and practical approach. Nat. Protoc. 2009, 4, 309-324.

8. Tung, Y.C.; Hsiao, A.Y.; Allen, S.G.; Torisawa, Y.S.; Ho, M.; Takayama, S. High-throughput 3D spheroid culture and drug testing using a 384 hanging drop array. Analyst 2011, 136, 473-478.

9. Thierbach, R.; Steinberg, P. Automated soft agar assay for the high-throughput screening of anticancer compounds. Anal. Biochem. 2009, 387, 318-320.

10. Kim, J.B. Three-dimensional tissue culture models in cancer biology. Semin. Canc. Biol. 2005, 15, 365-377.

11. Santini, M.T.; Rainaldi, G. Three-dimensional spheroid model in tumor biology. Pathobiology 1999, 67, 148-157.

12. Kunz-Schughart, L.A. Multicellular tumor spheroids: Intermediates between monolayer culture and in vivo tumor. Cell Biol. Int. 1999, 23, 157-161.

13. Friedrich, J.; Ebner, R.; Kunz-Schughart, L.A. Experimental anti-tumor therapy in 3-D: Spheroids - Old hat or new challenge? Int. J. Radiat. Biol. 2007, 83, 849-871.

14. Mueller-Klieser, W. Tumor biology and experimental therapeutics. Crit. Rev. Oncol. Hematol. 2000, 36, 123-139.

15. Kyle, A.H.; Huxham, L.A.; Chiam, A.S.; Sim, D.H.; Minchinton, A.I. Direct assessment of drug penetration into tissue using a novel application of three-dimensional cell culture. Canc. Res. 2004, 64, 6304-6309.

16. Minchinton, A.I.; Tannock, I.F. Drug penetration in solid tumours. Nat. Rev. Cancer 2006, 6, 583-592.

17. Toh, Y.C.; Zhang, C.; Zhang, J.; Khong, Y.M.; Chang, S.; Samper, V.D.; van Noort, D.; Hutmacher, D.W.; Yu, H. A novel 3D mammalian cell perfusion-culture system in microfluidic channels. Lab Chip 2007, 7, 302-309. 
18. Weaver, V.M.; Petersen, O.W.; Wang, F.; Larabell, C.A.; Briand, P.; Damsky, C.; Bissell, M.J. Reversion of the malignant phenotype of human breast cells in three-dimensional culture and in vivo by integrin blocking antibodies. J. Cell Biol. 1997, 137, 231-245.

19. Park, C.C.; Zhang, H.; Pallavicini, M.; Gray, J.W.; Baehner, F.; Park, C.J.; Bissell, M.J. Betal integrin inhibitory antibody induces apoptosis of breast cancer cells, inhibits growth, and distinguishes malignant from normal phenotype in three dimensional cultures and in vivo. Canc. Res. 2006, 66, 1526-1535.

20. Muranen, T.; Selfors, L.M.; Worster, D.T.; Iwanicki, M.P.; Song, L.; Morales, F.C.; Gao, S.; Mills, G.B.; Brugge, J.S. Inhibition of PI3K/mTOR leads to adaptive resistance in matrix-attached cancer cells. Canc. Cell 2012, 21, 227-239.

21. Lovitt, C.J.; Shelper, T.B.; Avery, V.M. Miniaturized three-dimensional cancer model for drug evaluation. Assay Drug Dev. Techn. 2013, 11, 435-448.

22. Barcellos-Hoff, M.H.; Aggeler, J.; Ram, T.G.; Bissell, M.J. Functional differentiation and alveolar morphogenesis of primary mammary cultures on reconstituted basement membrane. Development 1989, 105, 223-235.

23. Nelson, C.M.; Bissell, M.J. Modeling dynamic reciprocity: Engineering three-dimensional culture models of breast architecture, function, and neoplastic transformation. Semin. Canc. Biol. 2005, 15, 342-352.

24. Debnath, J.; Brugge, J.S. Modelling glandular epithelial cancers in three-dimensional cultures. Nat. Rev. Canc. 2005, 5, 675-688.

25. Debnath, J.; Mills, K.R.; Collins, N.L.; Reginato, M.J.; Muthuswamy, S.K.; Brugge, J.S. The role of apoptosis in creating and maintaining luminal space within normal and oncogeneexpressing mammary acini. Cell 2002, 111, 29-40.

26. Lee, G.Y.; Kenny, P.A.; Lee, E.H.; Bissell, M.J. Three-dimensional culture models of normal and malignant breast epithelial cells. Nat. Methods 2007, 4, 359-365.

27. Nirmalanandhan, V.S.; Duren, A.; Hendricks, P.; Vielhauer, G.; Sittampalam, G.S. Activity of anticancer agents in a three-dimensional cell culture model. Assay Drug Dev. Techn. 2010, 8 , 581-590.

28. Kenny, P.A.; Lee, G.Y.; Myers, C.A.; Neve, R.M.; Semeiks, J.R.; Spellman, P.T.; Lorenz, K.; Lee, E.H.; Barcellos-Hoff, M.H.; Petersen, O.W.; et al. The morphologies of breast cancer cell lines in three-dimensional assays correlate with their profiles of gene expression. Mol. Oncol. 2007, 1, 84-96.

29. Harma, V.; Virtanen, J.; Makela, R.; Happonen, A.; Mpindi, J.P.; Knuuttila, M.; Kohonen, P.; Lotjonen, J.; Kallioniemi, O.; Nees, M. A comprehensive panel of three-dimensional models for studies of prostate cancer growth, invasion and drug responses. PLoS One 2010, 5, e10431.

30. Burdett, E.; Kasper, F.K.; Mikos, A.G.; Ludwig, J.A. Engineering tumors: A tissue engineering perspective in cancer biology. Tissue Eng. B Rev. 2010, 16, 351-359.

31. Breslin, S.; O'Driscoll, L. Three-dimensional cell culture: The missing link in drug discovery. Drug Discov. Today 2013, 18, 240-249.

32. Meads, M.B.; Gatenby, R.A.; Dalton, W.S. Environment-mediated drug resistance: A major contributor to minimal residual disease. Nat. Rev. Canc. 2009, 9, 665-674. 
33. Zahreddine, H.; Borden, K.L. Mechanisms and insights into drug resistance in cancer. Front. Pharmacol. 2013, 4, 28.

34. Rebucci, M.; Michiels, C. Molecular aspects of cancer cell resistance to chemotherapy. Biochem. Pharmacol. 2013, 85, 1219-1226.

35. Di Nicolantonio, F.; Mercer, S.J.; Knight, L.A.; Gabriel, F.G.; Whitehouse, P.A.; Sharma, S.; Fernando, A.; Glaysher, S.; Di Palma, S.; Johnson, P.; et al. Cancer cell adaptation to chemotherapy. BMC Canc. 2005, 5, 78.

36. Mehta, G.; Hsiao, A.Y.; Ingram, M.; Luker, G.D.; Takayama, S. Opportunities and challenges for use of tumor spheroids as models to test drug delivery and efficacy. J. Contr. Release 2012, 164, 192-204.

37. Dhiman, H.K.; Ray, A.R.; Panda, A.K. Three-dimensional chitosan scaffold-based MCF-7 cell culture for the determination of the cytotoxicity of tamoxifen. Biomaterials 2005, 26, 979-986.

38. Horning, J.L.; Sahoo, S.K.; Vijayaraghavalu, S.; Dimitrijevic, S.; Vasir, J.K.; Jain, T.K.; Panda, A.K.; Labhasetwar, V. 3-d tumor model for in vitro evaluation of anticancer drugs. Mol. Pharm. 2008, 5, 849-862.

39. Barbone, D.; Yang, T.M.; Morgan, J.R.; Gaudino, G.; Broaddus, V.C. Mammalian target of rapamycin contributes to the acquired apoptotic resistance of human mesothelioma multicellular spheroids. J. Biol. Chem. 2008, 283, 13021-13030.

40. Howes, A.L.; Chiang, G.G.; Lang, E.S.; Ho, C.B.; Powis, G.; Vuori, K.; Abraham, R.T. The phosphatidylinositol 3-kinase inhibitor, px-866, is a potent inhibitor of cancer cell motility and growth in three-dimensional cultures. Mol. Canc. Ther. 2007, 6, 2505-2514.

41. Frankel, A.; Man, S.; Elliott, P.; Adams, J.; Kerbel, R.S. Lack of multicellular drug resistance observed in human ovarian and prostate carcinoma treated with the proteasome inhibitor ps-341. Clin. Canc. Res. 2000, 6, 3719-3728.

42. Pick1, M.; Ries, C.H. Comparison of 3D and 2D tumor models reveals enhanced HER2 activation in $3 \mathrm{D}$ associated with an increased response to trastuzumab. Oncogene 2009, 28, 461468.

43. Petersen, O.W.; Ronnov-Jessen, L.; Howlett, A.R.; Bissell, M.J. Interaction with basement membrane serves to rapidly distinguish growth and differentiation pattern of normal and malignant human breast epithelial cells. Proc. Natl. Acad. Sci. USA 1992, 89, 9064-9068.

44. Li, M.L.; Aggeler, J.; Farson, D.A.; Hatier, C.; Hassell, J.; Bissell, M.J. Influence of a reconstituted basement membrane and its components on casein gene expression and secretion in mouse mammary epithelial cells. Proc. Natl. Acad. Sci. USA 1987, 84, 136-140.

45. Emerman, J.T.; Pitelka, D.R. Maintenance and induction of morphological differentiation in dissociated mammary epithelium on floating collagen membranes. In Vitro 1977, 13, 316-328.

46. Sutherland, R.M.; McCredie, J.A.; Inch, W.R. Growth of multicell spheroids in tissue culture as a model of nodular carcinomas. J. Natl. Canc. Inst. 1971, 46, 113-120.

47. Ghosh, S.; Spagnoli, G.C.; Martin, I.; Ploegert, S.; Demougin, P.; Heberer, M.; Reschner, A. Three-dimensional culture of melanoma cells profoundly affects gene expression profile: A high density oligonucleotide array study. J. Cell Physiol. 2005, 204, 522-531. 
48. Lee, J.M.; Mhawech-Fauceglia, P.; Lee, N.; Parsanian, L.C.; Lin, Y.G.; Gayther, S.A.; Lawrenson, K. A three-dimensional microenvironment alters protein expression and chemosensitivity of epithelial ovarian cancer cells in vitro. Lab Invest. 2013, 93, 528-542.

49. Gaedtke, L.; Thoenes, L.; Culmsee, C.; Mayer, B.; Wagner, E. Proteomic analysis reveals differences in protein expression in spheroid versus monolayer cultures of low-passage colon carcinoma cells. J. Proteome Res. 2007, 6, 4111-4118.

50. Windus, L.C.; Glover, T.T.; Avery, V.M. Bone-stromal cells up-regulate tumourigenic markers in a tumour-stromal 3D model of prostate cancer. Mol. Canc. 2013, 12, 112.

51. Aoudjit, F.; Vuori, K. Integrin signaling inhibits paclitaxel-induced apoptosis in breast cancer cells. Oncogene 2001, 20, 4995-5004.

52. Sethi, T.; Rintoul, R.C.; Moore, S.M.; MacKinnon, A.C.; Salter, D.; Choo, C.; Chilvers, E.R.; Dransfield, I.; Donnelly, S.C.; Strieter, R.; et al. Extracellular matrix proteins protect small cell lung cancer cells against apoptosis: A mechanism for small cell lung cancer growth and drug resistance in vivo. Nat. Med. 1999, 5, 662-668.

53. Huanwen, W.; Zhiyong, L.; Xiaohua, S.; Xinyu, R.; Kai, W.; Tonghua, L. Intrinsic chemoresistance to gemcitabine is associated with constitutive and laminin-induced phosphorylation of fak in pancreatic cancer cell lines. Mol. Canc. 2009, 8, 125.

54. Thomas, F.; Holly, J.M.; Persad, R.; Bahl, A.; Perks, C.M. Fibronectin confers survival against chemotherapeutic agents but not against radiotherapy in du145 prostate cancer cells: Involvement of the insulin like growth factor-1 receptor. Prostate 2010, 70, 856-865.

55. Uhm, J.H.; Dooley, N.P.; Kyritsis, A.P.; Rao, J.S.; Gladson, C.L. Vitronectin, a glioma-derived extracellular matrix protein, protects tumor cells from apoptotic death. Clin. Canc. Res. 1999, 5, 1587-1594.

56. Hakanson, M.; Textor, M.; Charnley, M. Engineered 3D environments to elucidate the effect of environmental parameters on drug response in cancer. Integr. Biol. (Camb.) 2011, 3, 31-38.

57. Weigelt, B.; Lo, A.T.; Park, C.C.; Gray, J.W.; Bissell, M.J. HER2 signaling pathway activation and response of breast cancer cells to HER2-targeting agents is dependent strongly on the 3D microenvironment. Breast Canc. Res. Treat. 2010, 122, 35-43.

58. Chitcholtan, K.; Sykes, P.H.; Evans, J.J. The resistance of intracellular mediators to doxorubicin and cisplatin are distinct in 3D and 2D endometrial cancer. J. Transl. Med. 2012, 10, 38.

59. Knuchel, R.; Hofstadter, F.; Jenkins, W.E.; Masters, J.R. Sensitivities of monolayers and spheroids of the human bladder cancer cell line mgh-ul to the drugs used for intravesical chemotherapy. Canc. Res. 1989, 49, 1397-1401.

60. Dufau, I.; Frongia, C.; Sicard, F.; Dedieu, L.; Cordelier, P.; Ausseil, F.; Ducommun, B.; Valette, A. Multicellular tumor spheroid model to evaluate spatio-temporal dynamics effect of chemotherapeutics: Application to the gemcitabine/chk1 inhibitor combination in pancreatic cancer. BMC Canc. 2012, 12, 15.

61. Wen, Z.; Liao, Q.; Hu, Y.; You, L.; Zhou, L.; Zhao, Y. A spheroid-based 3-D culture model for pancreatic cancer drug testing, using the acid phosphatase assay. Braz. J. Med. Biol. Res. 2013, 46, 634-642. 
62. Mikhail, A.S.; Eetezadi, S.; Allen, C. Multicellular tumor spheroids for evaluation of cytotoxicity and tumor growth inhibitory effects of nanomedicines in vitro: A comparison of docetaxelloaded block copolymer micelles and taxotere(r). PLoS One 2013, 8, e62630.

63. Wang, F.; Hansen, R.K.; Radisky, D.; Yoneda, T.; Barcellos-Hoff, M.H.; Petersen, O.W.; Turley, E.A.; Bissell, M.J. Phenotypic reversion or death of cancer cells by altering signaling pathways in three-dimensional contexts. J. Natl. Canc. Inst. 2002, 94, 1494-1503.

64. Loessner, D.; Stok, K.S.; Lutolf, M.P.; Hutmacher, D.W.; Clements, J.A.; Rizzi, S.C. Bioengineered 3D platform to explore cell-ecm interactions and drug resistance of epithelial ovarian cancer cells. Biomaterials 2010, 31, 8494-8506.

65. Park, C.C.; Zhang, H.J.; Yao, E.S.; Park, C.J.; Bissell, M.J. Beta1 integrin inhibition dramatically enhances radiotherapy efficacy in human breast cancer xenografts. Canc. Res. 2008, 68, 4398-4405.

66. Huang, C.; Park, C.C.; Hilsenbeck, S.G.; Ward, R.; Rimawi, M.F.; Wang, Y.C.; Shou, J.; Bissell, M.J.; Osborne, C.K.; Schiff, R. Betal integrin mediates an alternative survival pathway in breast cancer cells resistant to lapatinib. Breast Canc. Res. 2011, 13, R84.

67. Lesniak, D.; Xu, Y.; Deschenes, J.; Lai, R.; Thoms, J.; Murray, D.; Gosh, S.; Mackey, J.R.; Sabri, S.; Abdulkarim, B. Beta1-integrin circumvents the antiproliferative effects of trastuzumab in human epidermal growth factor receptor-2-positive breast cancer. Canc. Res. 2009, 69, 8620-8628.

68. Zhang, H.; Ozaki, I.; Mizuta, T.; Matsuhashi, S.; Yoshimura, T.; Hisatomi, A.; Tadano, J.; Sakai, T.; Yamamoto, K. Beta 1-integrin protects hepatoma cells from chemotherapy induced apoptosis via a mitogen-activated protein kinase dependent pathway. Cancer 2002, 95, 896-906.

69. Predect: Novel complex models for cancer target validation. Available online: http://www.predect.eu/ (accessed on 4 February 2014).

70. Celli, J.P.; Rizvi, I.; Blanden, A.R.; Massodi, I.; Glidden, M.D.; Pogue, B.W.; Hasan, T. An imaging-based platform for high-content, quantitative evaluation of therapeutic response in $3 \mathrm{D}$ tumour models. Sci. Rep. 2014, 4, 3751.

71. Wenzel, C.; Riefke, B.; Grundemann, S.; Krebs, A.; Christian, S.; Prinz, F.; Osterland, M.; Golfier, S.; Rase, S.; Ansari, N.; et al. 3D high-content screening for the identification of compounds that target cells in dormant tumor spheroid regions. Exp. Cell Res. 2014, 323, 131-143.

72. Krausz, E.; de Hoogt, R.; Gustin, E.; Cornelissen, F.; Grand-Perret, T.; Janssen, L.; Vloemans, N.; Wuyts, D.; Frans, S.; Axel, A.; et al. Translation of a tumor microenvironment mimicking 3D tumor growth co-culture assay platform to high-content screening. J. Biomol. Screen. 2013, 18, $54-66$.

73. Horman, S.R.; To, J.; Orth, A.P. An hts-compatible 3D colony formation assay to identify tumor-specific chemotherapeutics. J. Biomol. Screen. 2013, 18, 1298-1308.

74. Godugu, C.; Patel, A.R.; Desai, U.; Andey, T.; Sams, A.; Singh, M. Algimatrix based 3D cell culture system as an in vitro tumor model for anticancer studies. PLoS One 2013, 8, e53708.

75. Anderson, S.N.; Towne, D.L.; Burns, D.J.; Warrior, U. A high-throughput soft agar assay for identification of anticancer compound. J. Biomol. Screen. 2007, 12, 938-945. 
76. Hongisto, V.; Jernstrom, S.; Fey, V.; Mpindi, J.P.; Kleivi Sahlberg, K.; Kallioniemi, O.; Perala, M. High-throughput 3D screening reveals differences in drug sensitivities between culture models of jimt1 breast cancer cells. PLoS One 2013, 8, e77232.

77. Longati, P.; Jia, X.; Eimer, J.; Wagman, A.; Witt, M.R.; Rehnmark, S.; Verbeke, C.; Toftgard, R.; Lohr, M.; Heuchel, R.L. 3D pancreatic carcinoma spheroids induce a matrix-rich, chemoresistant phenotype offering a better model for drug testing. BMC Canc. 2013, 13, 95.

78. Li, Q.; Chen, C.; Kapadia, A.; Zhou, Q.; Harper, M.K.; Schaack, J.; Labarbera, D.V. 3D models of epithelial-mesenchymal transition in breast cancer metastasis: High-throughput screening assay development, validation, and pilot screen. J. Biomol. Screen. 2011, 16, 141-154.

79. Herrmann, R.; Fayad, W.; Schwarz, S.; Berndtsson, M.; Linder, S. Screening for compounds that induce apoptosis of cancer cells grown as multicellular spheroids. J. Biomol. Screen. 2008, 13, $1-8$.

80. Asthana, A.; Kisaalita, W.S. Microtissue size and hypoxia in hts with 3D cultures. Drug Discov. Today 2012, 17, 810-817.

81. Hoque, M.T.; Windus, L.C.E.; Lovitt, C.J.; Avery, V.M. Pcaanalyser: A 2D-image analysis based module for effective determination of prostate cancer progression in $3 \mathrm{D}$ culture. PLoS One 2013, 8, e79865.

82. Han, J.; Chang, H.; Giricz, O.; Lee, G.Y.; Baehner, F.L.; Gray, J.W.; Bissell, M.J.; Kenny, P.A.; Parvin, B. Molecular predictors of 3D morphogenesis by breast cancer cell lines in 3D culture. PLoS Comput. Biol. 2010, 6, e1000684.

83. Li, X.; Zhang, X.; Zhao, S.; Wang, J.; Liu, G.; Du, Y. Micro-scaffold array chip for upgrading cell-based high-throughput drug testing to 3D using benchtop equipment. Lab Chip 2014, 14, 471-481.

84. Xu, Z.; Gao, Y.; Hao, Y.; Li, E.; Wang, Y.; Zhang, J.; Wang, W.; Gao, Z.; Wang, Q. Application of a microfluidic chip-based 3D co-culture to test drug sensitivity for individualized treatment of lung cancer. Biomaterials 2013, 34, 4109-4117.

85. Bersini, S.; Jeon, J.S.; Dubini, G.; Arrigoni, C.; Chung, S.; Charest, J.L.; Moretti, M.; Kamm, R.D. A microfluidic 3D in vitro model for specificity of breast cancer metastasis to bone. Biomaterials 2014, 35, 2454-2461.

86. Rimann, M.; Angres, B.; Patocchi-Tenzer, I.; Braum, S.; Graf-Hausner, U. Automation of 3D cell culture using chemically defined hydrogels. J. Lab. Autom. 2013, 19, 191-197.

87. Deiss, F.; Mazzeo, A.; Hong, E.; Ingber, D.E.; Derda, R.; Whitesides, G.M. Platform for high-throughput testing of the effect of soluble compounds on 3D cell cultures. Anal. Chem. 2013, 85, 8085-8094.

88. Wlodkowic, D.; Cooper, J.M. Tumors on chips: Oncology meets microfluidics. Curr. Opin. Chem. Biol. 2010, 14, 556-567.

89. Correa de Sampaio, P.; Auslaender, D.; Krubasik, D.; Failla, A.V.; Skepper, J.N.; Murphy, G.; English, W.R. A heterogeneous in vitro three dimensional model of tumour-stroma interactions regulating sprouting angiogenesis. PLoS One 2012, 7, e30753.

90. Salameh, T.S.; Le, T.T.; Nichols, M.B.; Bauer, E.; Cheng, J.; Camarillo, I.G. An ex vivo co-culture model system to evaluate stromal-epithelial interactions in breast cancer. Int. J. Canc. 2013, 132, 288-296. 
91. Shekhar, M.P.; Santner, S.; Carolin, K.A.; Tait, L. Direct involvement of breast tumor fibroblasts in the modulation of tamoxifen sensitivity. Am. J. Pathol. 2007, 170, 1546-1560.

92. Li, L.; Lu, Y. Optimizing a 3D culture system to study the interaction between epithelial breast cancer and its surrounding fibroblasts. J. Canc. 2011, 2, 458-466.

93. Yamada, K.M.; Cukierman, E. Modeling tissue morphogenesis and cancer in 3D. Cell 2007, 130, 601-610.

94. Butcher, D.T.; Alliston, T.; Weaver, V.M. A tense situation: Forcing tumour progression. Nat. Rev. Canc. 2009, 9, 108-122.

95. Paszek, M.J.; Zahir, N.; Johnson, K.R.; Lakins, J.N.; Rozenberg, G.I.; Gefen, A.; Reinhart-King, C.A.; Margulies, S.S.; Dembo, M.; Boettiger, D.; et al. Tensional homeostasis and the malignant phenotype. Canc. Cell 2005, 8, 241-254.

96. van der Kuip, H.; Murdter, T.E.; Sonnenberg, M.; McClellan, M.; Gutzeit, S.; Gerteis, A.; Simon, W.; Fritz, P.; Aulitzky, W.E. Short term culture of breast cancer tissues to study the activity of the anticancer drug taxol in an intact tumor environment. BMC Canc. 2006, 6, 86.

97. Biggs, T.; Foreman, J.; Sundstrom, L.; Regenass, U.; Lehembre, F. Antitumor compound testing in glioblastoma organotypic brain cultures. J. Biomol. Screen. 2011, 16, 805-817.

98. Sundstrom, L.; Biggs, T.; Laskowski, A.; Stoppini, L. Organdots-An organotypic 3D tissue culture platform for drug development. Expert Opin. Drug Discov. 2012, 7, 525-534.

99. Puig, I.; Chicote, I.; Tenbaum, S.P.; Arques, O.; Herance, J.R.; Gispert, J.D.; Jimenez, J.; Landolfi, S.; Caci, K.; Allende, H.; et al. A personalized preclinical model to evaluate the metastatic potential of patient-derived colon cancer initiating cells. Clin. Canc. Res. 2013, 19, 6787-6801.

100. Lin, D.; Wyatt, A.W.; Xue, H.; Wang, Y.; Dong, X.; Haegert, A.; Wu, R.; Brahmbhatt, S.; Mo, F.; Jong, L.; et al. High fidelity patient-derived xenografts for accelerating prostate cancer discovery and drug development. Canc. Res. 2014, 74, 1272-1283.

101. Lengyel, E.; Burdette, J.E.; Kenny, H.A.; Matei, D.; Pilrose, J.; Haluska, P.; Nephew, K.P.; Hales, D.B.; Stack, M.S. Epithelial ovarian cancer experimental models. Oncogene 2013, 12, 321.

(C) 2014 by the authors; licensee MDPI, Basel, Switzerland. This article is an open access article distributed under the terms and conditions of the Creative Commons Attribution license (http://creativecommons.org/licenses/by/3.0/). 